\title{
Mechanism of Localized Corrosion and Phase Transformation of Tube-to-Tube Sheet Welds of Hyper Duplex Stainless Steel in Acidified Chloride Environments
}

\author{
Jin-Seung Kim ${ }^{1}$, Soon-Tae Kim ${ }^{1, *}$, In-Sung Lee ${ }^{1}$, Seok-Hwan Jang ${ }^{1}$, \\ Yong-Soo Park ${ }^{1}$, Kwang-Tae Kim ${ }^{2}$ and Young-Sub Kim ${ }^{3}$ \\ ${ }^{1}$ Department of Materials Science and Engineering, Yonsei University, \\ 134 Shinchon-dong, Seodaemun-gu, Seoul 120-749, Korea \\ ${ }^{2}$ Stainless Steel Research Group, POSCO Technical Research Laboratories, \\ Goedong-dong, Nam-Gu, Pohang, Gyeongbuk 790-785, Korea \\ ${ }^{3}$ Material Research Division, Research Institute of Industrial Science and Technology, \\ San 32 Hyoja-dong, Nam-gu, Pohang 790-600, Korea
}

The mechanism of localized corrosion and phase transformation of tube-to-tube sheet welds of hyper duplex stainless steel (HDSS) were investigated in acidified chloride environments. The HDSS tube-to-tube sheet welded with an Ar shielding gas without a filler metal, which increases the ferrite content, $\mathrm{Cr}_{2} \mathrm{~N}$ and pitting resistance equivalent number (PREN) difference between the two phases, demonstrated the lower corrosion resistance than that with Ar shielding gas with a filler metal. The pitting corrosion of the weld metal (WM) in the HDSS tube-to-tube sheet welded using a pure Ar shielding gas with a filler metal occurred at the dendrite core (DC) that $\mathrm{Cr}$ and Mo were depleted and at the region adjacent to Mu phase that Mo and W were depleted. The localized corrosion was selectively initiated at the $\alpha$-phase because the PREN value of the $\alpha$-phase was much smaller than that of the $\gamma$-phase, irrespective of the chemical compositions of the shielding, and the areas of the WM, heat affected zone (HAZ) and base metal (BM) (except for the WM in the HDSS tube-to-tube sheet welded using Ar with a filler metal) [doi:10.2320/matertrans.M2012243]

(Received July 12, 2012; Accepted September 18, 2012; Published November 2, 2012)

Keywords: stainless steel, localized corrosion, filler metal, shielding gas, electron probe micro-analyzer

\section{Introduction}

Duplex stainless steels (DSSs) with nearly equal fraction of ferrite $(\alpha)$ phase and austenite $(\gamma)$ phase have been increasingly being used for various applications such as desalination facilities, the off-shore petroleum industry, power plants and chemical plants due to their high resistance to stress corrosion cracking and pitting corrosion, good weldability, excellent mechanical properties and relatively low cost owing to the addition of low $\mathrm{Ni}$, as compared with austenite stainless steels. ${ }^{1-3)}$

In general, it is well known that super duplex stainless steels such as UNS S32750, UNS S32760 and UNS S32550 are defined as duplex stainless steels with a PREN (Pitting Resistance Equivalent Number $(\mathrm{PREN})=\left[\begin{array}{ll}\operatorname{mass} \% & \mathrm{Cr}\end{array}\right]+$ $\left.3.3([\operatorname{mass} \% \mathrm{Mo}]+0.5[\operatorname{mass} \% \mathrm{~W}])+16 \operatorname{mass} \% \mathrm{~N}^{4,5)}\right)$ of 40-45. Hyper duplex stainless steel (HDSS) such as UNS S32707 is defined as a highly alloyed duplex stainless steel with a PREN in excess of 45.4. The corrosion resistances of duplex stainless steels are determined by the fraction of the $\alpha$-phase and $\gamma$-phase and by the $\mathrm{Cr}$ and Mo depleted zone adjacent to the secondary phases such as detrimental intermetallic phases $(\sigma, \mathrm{X})$, carbides, and nitrides.

However, there are some inevitable issues with the DSS including that the localized corrosion resistances of the weld metal (WM) and heat-affected zone (HAZ) in the DSS tubeto-tube sheet during solidification after welding without a filler wire deteriorate significantly due to the high ferrite content and $\mathrm{Cr}_{2} \mathrm{~N}$ precipitates in these areas, when compared with that of the corresponding base metal (BM).

*Corresponding author, E-mail: stkim78@yonsei.ac.kr
Accordingly, when DSSs are welded, the heat input, ${ }^{6-11)}$ post-weld heat-treatment $(\mathrm{PWHT})^{11-13)}$ and use of a filler metal $^{14)}$ can significantly affect the resistance to pitting corrosion of DSSs. Control over the balance of the $\gamma$-phase and $\alpha$-phase in the WM and HAZ is important from a corrosion viewpoint, because the corrosion resistance deteriorates with a high content of the $\alpha$-phase.

It was reported that the presence of chromium-rich nitrides $\left(\mathrm{Cr}_{2} \mathrm{~N}\right)$ is observed over a wide range of cooling rates and the effect is particularly evident for microstructures with a high ferrite content, which are usually the result of fast cooling rates. ${ }^{15,16)}$ These chromium rich nitrides also significantly decrease the impact toughness and pitting corrosion resistance. A risk of $\mathrm{Cr}_{2} \mathrm{~N}$ formation in the $\alpha$-phase is also noted with an increase in the $\alpha$-phase and increased nitrogen levels due to the lower solubility of nitrogen in the $\alpha$-phase. However, high cooling rates do reduce $\sigma$-phase precipitation.

Hence, it is important to quantitatively verify the mechanisms underlying the effects of shielding gas and filler metal on the microstructure and localized corrosion of the difference in the corrosion resistance between the two phases and the $\mathrm{Cr}$-depleted zone adjacent to $\mathrm{Cr}_{2} \mathrm{~N}$ and in the WM and HAZ of the HDSS tube-to-tube sheet welds.

In this work, to elucidate the mechanism of localized corrosion and phase transformation of the HDSS tube-to-tube sheet welds investigated in acidified chloride environments, a metallographic examination, a potentiodynamic polarization test, critical pitting and crevice temperature tests, scanning electron microscope and energy dispersive spectroscope (SEM-EDS) analyses, a scanning Auger multiprobe (SAM) analysis and an electron probe micro-analyzer (EPMA) were performed. 
Table 1 Chemical composition of high-performance duplex stainless steel and commercial Ni-base filler (mass\%).

\begin{tabular}{|c|c|c|c|c|c|c|c|c|c|c|c|c|c|}
\hline & $\mathrm{C}$ & $\mathrm{Cr}$ & $\mathrm{Ni}$ & Mo & W & $\mathrm{N}$ & $\mathrm{Mn}$ & $\mathrm{Si}$ & $\mathrm{Ce}$ & $\mathrm{La}$ & $\mathrm{Ba}$ & $\mathrm{Fe}$ & PREN $^{* 1}$ \\
\hline HDSS & 0.02 & 27.0 & 7.23 & 2.57 & 3.23 & 0.34 & 1.96 & 0.20 & 0.0137 & 0.0045 & 0.0006 & Bal. & 51.0 \\
\hline $\begin{array}{l}\text { ERNiCr } \\
\text { Mo-4*2 }\end{array}$ & 0.013 & 16.0 & Bal. & 16.0 & 4.0 & - & - & - & - & - & - & 5.0 & - \\
\hline
\end{tabular}

${ }^{* 1} \mathrm{PREN}=\operatorname{mass} \% \mathrm{Cr}+3.3(\operatorname{mass} \% \mathrm{Mo}+0.5 \operatorname{mass} \% \mathrm{~W})+30 \operatorname{mass} \% \mathrm{~N}$

${ }^{*}$ The commercial Ni-based filler metal

\section{Experimental Procedures}

\subsection{Calculation of phase diagram and the equilibrium fractions of each phase}

In order to predict the phase stability and solidification mode of the HDSS alloy during solidification after welding, the phase diagram and equilibrium fractions of each phase were calculated against the temperature for the HDSS alloy using a commercial Thermo-Calc software package. Its procedure is as follows: The chemical compositions of not only 27 mass \% Cr but also 7.23 mass\% Ni, 2.57 mass\% Mo, 3.23 mass \% W, 1.96 mass\% Mn, 0.2 mass \% Si, 0.02 mass\% C, 0.34 mass \% N are input into the Thermo-Calc Software. After this procedure is successfully completed, the phase diagram of $\mathrm{Cr}$ (mass\%) vs. temperature (K) is plotted.

\subsection{Materials}

To prepare the HDSS tube-to-tube sheet welds, tubes with and outer diameter of $19.05 \mathrm{~mm}$ and thickness of $1.5 \mathrm{~mm}$ were welded using the autogenous gas tungsten arc welding (GTAW) method and plates with a thickness of $8 \mathrm{~mm}$ were hot rolled. Thirty holes were drilled in the hot rolled plates.

Then, the holes were drilled in the plates. For the comparative conditions of the shielding gas and a filler metal (ERNiCrMo 4 from a Ni-based alloy), the tubes were inserted into the holes and were then expanded via rolling. The tubes and tube sheets were joined using the GTAW method with a heat input of $0.036 \mathrm{~kJ} / \mathrm{mm}$, using an Ar shielding gas without a filler metal, and a heat input of $0.35 \mathrm{~kJ} / \mathrm{mm}$, using an $\mathrm{Ar}$ shielding gas with the filler metal.

The heat input $(0.036 \mathrm{~kJ} / \mathrm{mm})$ of the HDSS tube-to-tube sheet welded using an Ar shielding gas without a filler metal was calculated using the following formula.

$$
H=60 E I / 1000 S
$$

( $H$; heat input $(0.036 \mathrm{~kJ} / \mathrm{mm}), E$; arc voltage $(9 \mathrm{~V}), I$; arc current $(85 \mathrm{~A}), S$; travel speed $(1260 \mathrm{~mm} / \mathrm{min}))$

The heat input $(0.35 \mathrm{~kJ} / \mathrm{mm})$ of the HDSS tube-to-tube sheet welded using an Ar shielding gas with a filler metal was calculated using the formula (1). (H; heat input $(0.35 \mathrm{~kJ} / \mathrm{mm}$, $E$; arc voltage $(8.7 \mathrm{~V}), I$; arc current $(58 \mathrm{~A}), S$; travel speed $(87 \mathrm{~mm} / \mathrm{min}))$

Figure 1 shows the configuration of the HDSS tube-to-tube sheet welds manufactured by the above welding conditions.

The chemical compositions of the HDSS with PREN 51, and a commercial Ni-base filler metal (ERNiCrMo) are presented in Table 1.

\subsection{Microstructural characterization}

To observe the optical microstructures of the weld metal (WM), heat affected zone (HAZ) and base metal (BM) in the

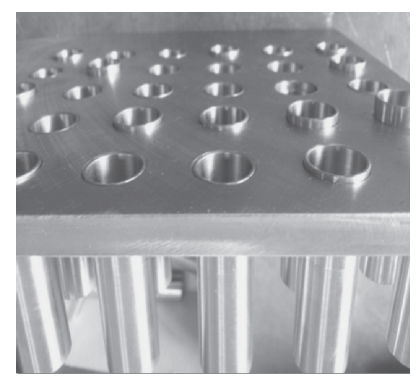

(a)

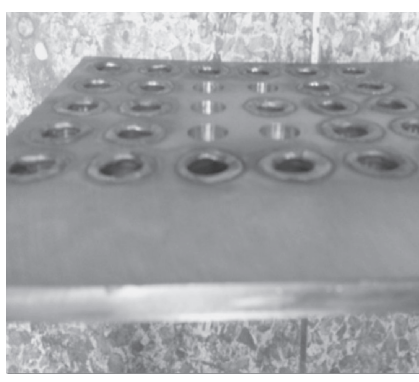

(b)
Fig. 1 Configuration of the HDSS tube-to-tube sheet welds: (a) before gas tungsten arc welding and (b) after gas tungsten arc welding.

HDSS welds, the tubes were electrolytically etched using 10 mass $\% \mathrm{KOH}$. The ferrite $(\alpha)$ and austenite $(\gamma)$ volume fractions were calculated using the method of manual point count according to the ASTM E562 ${ }^{17)}$ as follows: the magnification of the micrograph was 500 times and the grid size (number of points, PN) was 25. Any points that fell on the boundary were counted as half $(0.5)$. The chemical compositions of the $\alpha$-phase and $\gamma$-phase were analyzed using a JEOL JSM 700 SEM and an OXFORD instruments INCA X-art (51-ADD0069) EDS attached to a SEM. The nitrogen (N) content was analyzed using a Perkin-Elmer PHI 610 SAM. Ar sputtering was performed under the conditions of $10 \mathrm{KeV}, 10 \mathrm{nA}$, and $30^{\circ}$ tilt angle. Sputtering rate was $0.7 \mathrm{~nm} / \mathrm{min}$ from sputtering time of $0 \mathrm{~min}$ to that of $10 \mathrm{~min}$ and $3.5 \mathrm{~nm} / \mathrm{min}$ from sputtering time of $10 \mathrm{~min}$ to that of $20 \mathrm{~min}$. Relative sensitivity factors (RSF) of the $\mathrm{N}$ is 0.161 and RSF of $\mathrm{O}$ is 0.212 . The analyzed area size is approximately $2 \mu \mathrm{m}$.

The $\mathrm{Mu}(\mu)$ phases formed in the WM of the HDSS tubeto-tube sheet welds during the GTAW with filler metal were analyzed using a JEOL JSM 840A back-scattered electron (BSE) and a SHIMADZU EPMA-1600 EPMA.

The $\mathrm{Cr}_{2} \mathrm{~N}$ precipitates formed in the HDSS tube during the GTAW were analysed using a carbon replica technique and a thin foil technique with a transmission electron microscopy (a JEOL JM2100F TEM). The carbon replica was prepared by electrolytically etching the polished samples with an etchant of 10 mass\% $\mathrm{KOH}$. The thin foil specimens were prepared electrolytically at $25 \mathrm{~V}$ in $10 \%$ perchloric acid plus $90 \%$ methyl alcohol.

\subsection{Corrosion tests}

In order to measure the electrochemical parameters of the HDSS welds, a potentiodynamic anodic polarization test was performed using an EG\&G PAR 263A potentiostat in a deaerated $0.5 \mathrm{~N} \mathrm{HCl}+1 \mathrm{~N} \mathrm{NaCl}$ solution at $333 \mathrm{~K}$ according to ASTM G 5. ${ }^{18)}$ The test was undertaken using the welded 
zone $(\mathrm{WM}+\mathrm{HAZ}+\mathrm{BM})$ with an exposed area of $0.5 \mathrm{~cm}^{2}$. The test was conducted at a potential range of $-0.65 \mathrm{~V}_{\mathrm{SCE}^{-}}$ $+1.0 \mathrm{~V}_{\mathrm{SCE}}$ at a scanning rate of $0.06 \mathrm{~V} / \mathrm{min}$, using a saturated calomel electrode (SCE). A critical pitting temperature (CPT) test was performed in 6 mass $\% \mathrm{FeCl}_{3}+1$ mass $\% \mathrm{HCl}$ with a $\mathrm{pH}$ level of 0 according to the ASTM G48-Method E. ${ }^{19)}$ The CPT test was undertaken the welded zone (WM + HAZ + $\mathrm{BM}$ ) and BM. A critical crevice temperature (CCT) test was performed in 6 mass $\% \mathrm{FeCl}_{3}+1$ mass $\% \mathrm{HCl}$ according to the ASTM G 48-Method F. ${ }^{19)}$ The CCT test was undertaken using the WM and BM. The pitting and crevice corrosion were considered to be present if the local attack is $0.025 \mathrm{~mm}$ or more in depth and the mass loss corrosion rates were greater than or equal to $0.0001 \mathrm{~g} / \mathrm{cm}^{2}$. The deepest pits and crevices were measured using a calibrated needle point micrometer gage.

The optical microscope and SEM-EDS were used to observe the initiation and propagation of localized corrosion in the specimen after undertaking the potentiodynamic anodic polarization test and CPT test.

\section{Results and Discussion}

\subsection{Calculation of the phase diagram and equilibrium fraction of each phase}

The phase diagram of the HDSS alloy was calculated using the Thermo-Calc Software package, and it provides a roadmap of the metallurgical behavior (Fig. 2(a)). A sectional view of the 27 mass\% Cr illustrates that the alloy solidifies primarily as an $\alpha$-phase and some of the $\alpha$-phase transforms to a $\gamma$-phase with a temperature decrease. Accordingly, the solidification mode of the HDSS alloy can be considered as a type of FA mode. As the temperature decreases further, the $\alpha$-phase decomposes into a $\sigma$-phase $(\sigma)$ and secondary austenite $\left(\gamma_{2}\right)$ according to the eutectoid reaction.

$$
\text { FA mode: } \begin{aligned}
\mathrm{L} & \rightarrow \mathrm{L}+\alpha \rightarrow \mathrm{L}+\alpha+\gamma \rightarrow \alpha+\gamma \\
& \rightarrow \alpha+\gamma_{2}+\sigma \rightarrow \gamma_{2}+\sigma
\end{aligned}
$$

As the temperature of the solution heat-treatment decreases in the region with the dual $\gamma / \alpha$-phases, the volume fraction of the $\alpha$-phase decreases and that of the $\gamma$-phase increases. The equilibrium fractions of each phase against the temperature for the HDSS alloy were calculated using the Thermo-Calc Software package (Fig. 2(b)). It was predicted that the optimum temperature for the solution heat-treatment in order to obtain the desired microstructure of 50 vol\% $\gamma$-phase and 50 vol\% $\alpha$-phase is $1363 \mathrm{~K}$ and the $\mathrm{Cr}_{2} \mathrm{~N}$ precipitate at about $1273 \mathrm{~K}$.

\subsection{Phase transformation of the HDSS tube-to-tube sheet welds during the GTAW}

Figure 3 shows the optical microstructures of the HDSS tube-to-tube sheet welds. The $\gamma$-phases formed in the BM were elongated in the cold rolling direction, irrespective of the shielding gas composition and filler metal. As presented in Fig. 4, the content ( $85 \mathrm{vol} \%$ ) of the $\alpha$-phases in the WM of the HDSS tube-to-tube sheet welded with the Ar shielding gas without a filler metal demonstrated the greater increases, compared with that of the BM in the HDSS tube-to-tube sheet welds $(50 \mathrm{vol} \%)$.
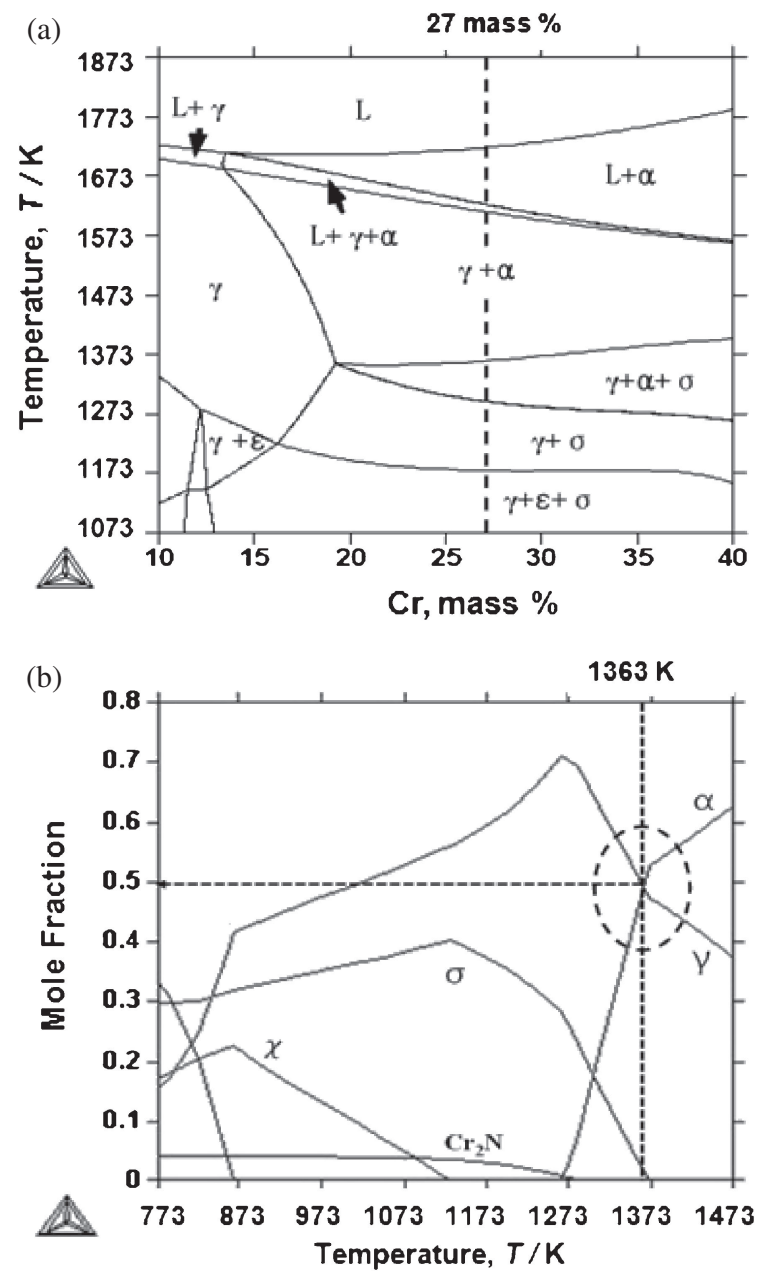

Fig. 2 (a) Calculation of the phase diagram for the HDSS alloy using a Thermo-Calc software package, and (b) calculation of the equilibrium fractions of each phase for the HDSS alloy using a Thermo-Calc software package.

The results of the TEM analyses of the $\mathrm{Cr}_{2} \mathrm{~N}$ formed in the WM of the HDSS tube-to-tube sheet after welding using pure Ar demonstrate that all precipitates were rod-like $\mathrm{Cr}$ nitrides (Figs. 5(a) and 5(b)). Neither carbides nor intermetallic compounds such as $\sigma$-phases and $\chi$-phases were detected in the WM. Based on the diffraction pattern analysis (Fig. 5(c)), the $\mathrm{Cr}_{2} \mathrm{~N}$ has a hexagonal close packed (HCP) structure. A Cr depleted zone, which decreases the corrosion resistance adjacent to the $\mathrm{Cr}_{2} \mathrm{~N}$, was observed (Fig. 5(d)). Furthermore, while the nitrogen is nearly completely solutionized in the $\gamma$ phase in the DSS, it is rarely solutionized in the $\alpha$-phase; the causes of this are as follows. The $\mathrm{N}$ atoms in the $\gamma$-phase with face centered cubic (FCC) lattices occupy the octahedral interstitial sites, leading to a $\mathrm{N}$ saturated $\gamma$-phase compared with that of the $\alpha$-phase with body centered cubic (BCC) lattices, because the octahedral interstices of the FCC lattice are approximately three times larger than those of the BCC lattice. The nitrogen solubility in the $\alpha$-phase has very low of maximum of 0.05 mass $\%{ }^{21)}$ Accordingly, the content of the $\alpha$-phase in the WM of the HDSS tube-to-tube sheet welded using pure Ar is much larger than that of the tube-to-tube sheet welded using Ar with a filler metal.

The content ( $63 \mathrm{vol} \%$ ) of the $\alpha$-phases in the HAZ of the HDSS tube-to-tube sheet welded using pure Ar with a filler 


\begin{tabular}{|c|c|c|c|}
\hline & BM & WM and $\mathrm{HAZ}$ & $\mathbf{W} \mathbf{M}$ \\
\hline (a) & 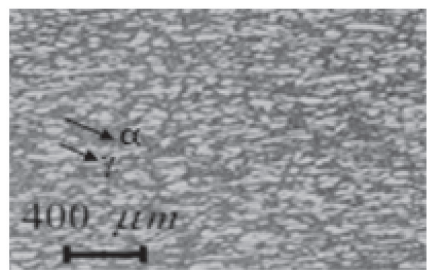 & $\begin{array}{l}\text { WM } \\
0-19 \\
400 \mathrm{Mm} \quad \mathrm{BM}\end{array}$ & $400 \mathrm{\mu m}$ \\
\hline (b) & $400 \mu \mathrm{mm}$ & $40^{--}$ & $400 \mu \mathrm{m}$ \\
\hline
\end{tabular}

Fig. 3 The optical microstructures of the HDSS tube-to-tube sheet welds: (a) welded with Ar without filler metal, ${ }^{20)}$ and (b) welded with Ar with filler metal. *Base Metal: BM, Heat Affected Zone: HAZ, Weld Metal: WM.

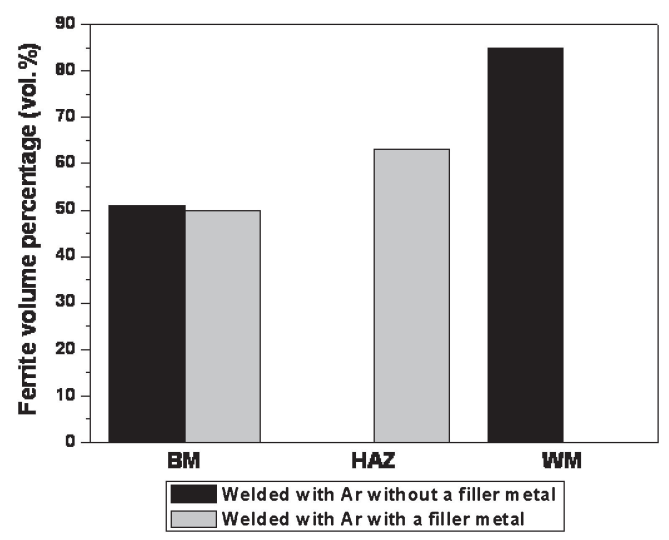

Fig. 4 The ferrite volume percentage of the HDSS tube-to-tube sheet welds.

metal was increased, when compared with that ( $49 \mathrm{vol} \%)$ of the BM in the HDSS tube-to-tube sheet welds. Furthermore, the width of HAZ in the HDSS tube-to-tube sheet welded using pure Ar with a filler metal was increased much larger than that of the HDSS tube-to-tube sheet welded using pure Ar without a filler metal because the heat input $(0.35 \mathrm{~kJ} / \mathrm{mm})$ of the former is much higher than that $(0.036 \mathrm{~kJ} / \mathrm{mm})$ of the latter. The HAZ in the HDSS tube-to-tube sheet welded using pure Ar without a filler metal doesn't exist nearly due to lower heat input.

Figure 6 shows the back scattered electron (BSE) image and the electron probe micro-analyzer (EPMA) line analyses of the weld metal (WM) in the HDSS tube-to-tube sheet welded using a pure Ar shielding gas with a filler metal. As presented in Fig. 6(a), the weld metal of the tube-to-tube sheet welds obtained by solidification after the GTAW forms cells that are composed of the interdendritic regions (IR) and dendritic regions (DR). In the interdendritic region, $\mathrm{Cr}$ and Mo were enriched whereas $\mathrm{Ni}$ and $\mathrm{Fe}$ were depleted. Conversely, in the dendrite core, $\mathrm{Cr}$ and Mo were depleted whereas Ni and Fe were enriched (Fig. 6(b)). The content of $\mathrm{Cr}$ and $\mathrm{Mo}$ in the dendrite core (DC) decreased greatly, compared with that in the other regions. In particular, the
Table 2 Chemical composition (mass \%) of the interdendritic region (IR), dendritic region (DR) and $\mathrm{Mu}(\mu)$ phase in the weld metal of the HDSS tube-to-tube sheet welded with Ar with a filler metal.

\begin{tabular}{|c|c|c|c|c|c|}
\hline & $\mathrm{Cr}$ & $\mathrm{Fe}$ & $\mathrm{Ni}$ & Mo & W \\
\hline Substrate & 16 & 5 & Bal. & 16 & 4 \\
\hline IR $1^{* 1}$ & 17.3 & 13.9 & 44.3 & 19.7 & 4.8 \\
\hline $\mathrm{DR} 1^{* 2}$ & 15.0 & 16.5 & 51.3 & 13.6 & 3.5 \\
\hline $\operatorname{IR~} 2^{* 3}$ & 17.5 & 13.2 & 44.4 & 20.2 & 4.8 \\
\hline DR $2^{* 4}$ & 15.9 & 16.1 & 52.3 & 12.6 & 3.2 \\
\hline $\mathrm{Mu}(\mu)$ phase & 17.8 & 9.7 & 29.9 & 36.4 & 6.2 \\
\hline
\end{tabular}

${ }^{*}$ Interdendritic Region 1: IR 1

${ }^{*}$ Dendritic Region 1: DR 1

${ }^{*_{3}}$ Interdendritic Region 2: IR 2

${ }^{*}$ Dendritic Region 2: DR 2

intermetallic compounds such as $\mathrm{Mu}(\mu)$ phases in the interdendritic regions were observed. ${ }^{22}$ ) The $\mathrm{Mo}$ and $\mathrm{W}$ in the $\mathrm{Mu}$ phase were enriched much more than those in the IR (Table 2). The $\mu$-phase is a topologically-closed-packed (TCP) phase in nickel base alloys. With a hexagonal system, the phase has the rhombohedral lattice with $a=0.476 \mathrm{~nm}$ and $c=2.56 \mathrm{~nm}^{23)}$ The presence of the $\mu$-phase in some nickel base alloys is unavoidable due to the high concentration of tungsten and molybdenum. Generally, when the content of tungsten and molybdenum is more than 3.5 mass $\%$, the $\mu$-phase is the main TCP phase instead of the sigma $(\sigma)$ phase. $^{24)}$ The presence of $\mu$ phase has been found to be detrimental to properties of the alloys such as rupture strength, tensile ductility at room temperature, impact toughness and corrosion resistance. ${ }^{25,26)}$

\subsection{The resistance to localized corrosion of the HDSS tube-to-tube sheet welds}

Figure 7 shows the potentiodynamic anodic polarization behavior of the HDSS tube-to-tube sheet welds in a deaerated $0.5 \mathrm{~N} \mathrm{HCl}+1 \mathrm{~N} \mathrm{NaCl}$ at $333 \mathrm{~K}$ according to ASTM G 5. In general, the pitting potential $\left(E_{\mathrm{p}}\right)$ is defined as the breakdown potential that destroys a passive film. As the $E_{\mathrm{p}}$ of an alloy 


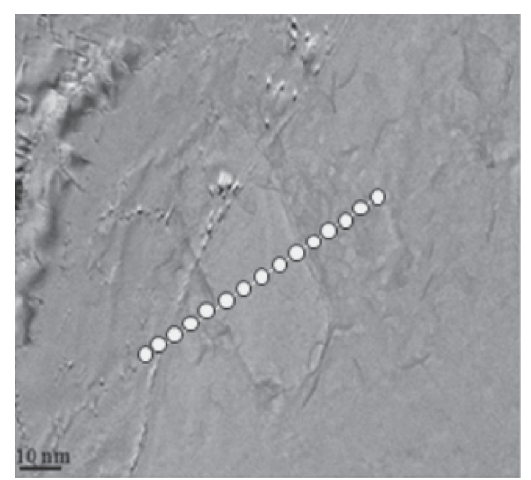

(a)

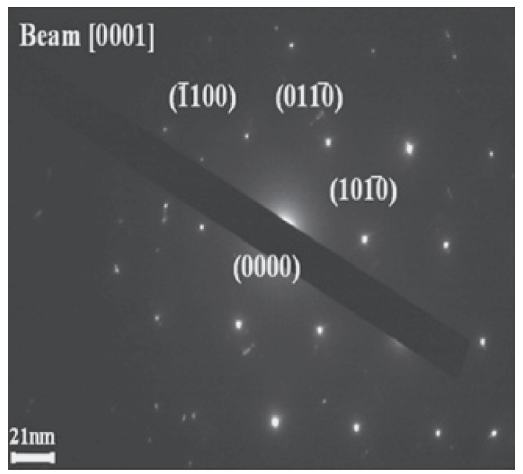

(c)

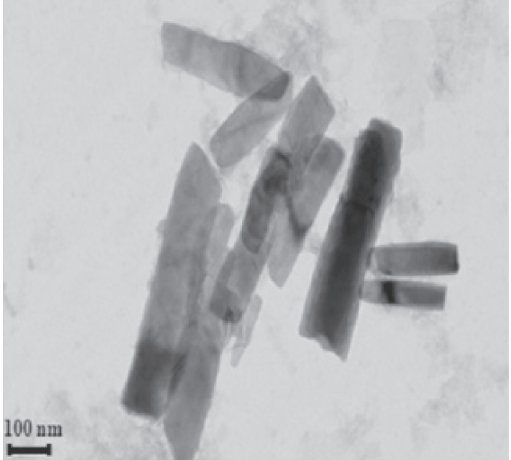

(b)

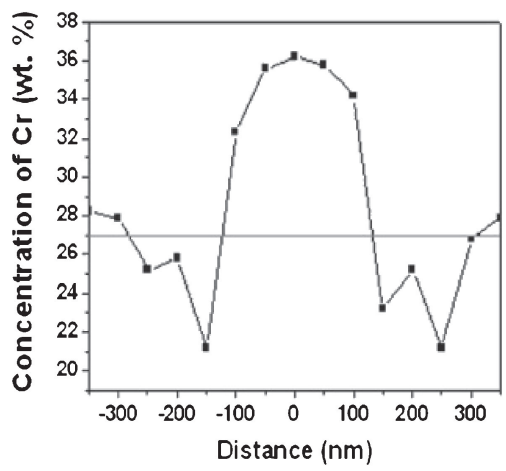

(d)

Fig. 5 TEM analyses of $\mathrm{Cr}_{2} \mathrm{~N}$ precipitated in the weld metal of the HDSS tube-to-tube sheet after welding with pure Ar.: ${ }^{20)}$ (a) the morphology of $\mathrm{Cr}_{2} \mathrm{~N}$ observed by a thin film technique, (b) the replica technique, (c) the diffraction pattern and (d) the line analysis of $\mathrm{Cr}$ adjacent to $\mathrm{Cr}_{2} \mathrm{~N}$.

(a)

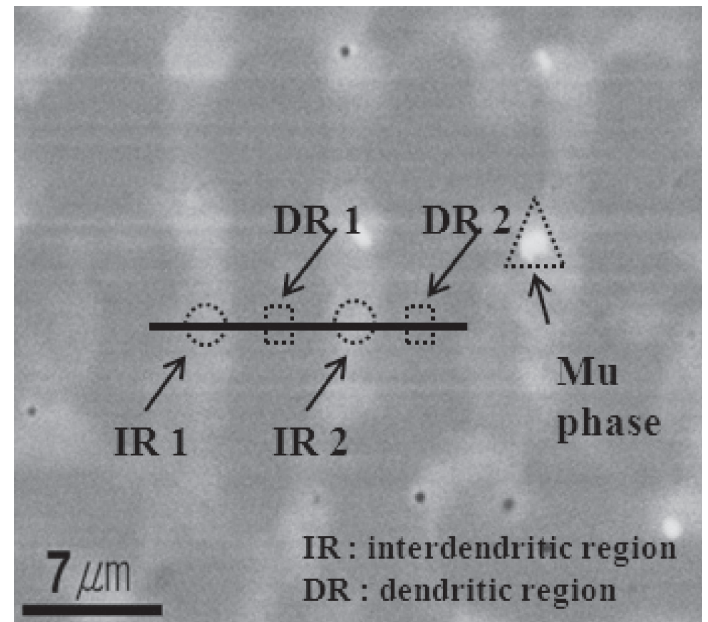

(b)

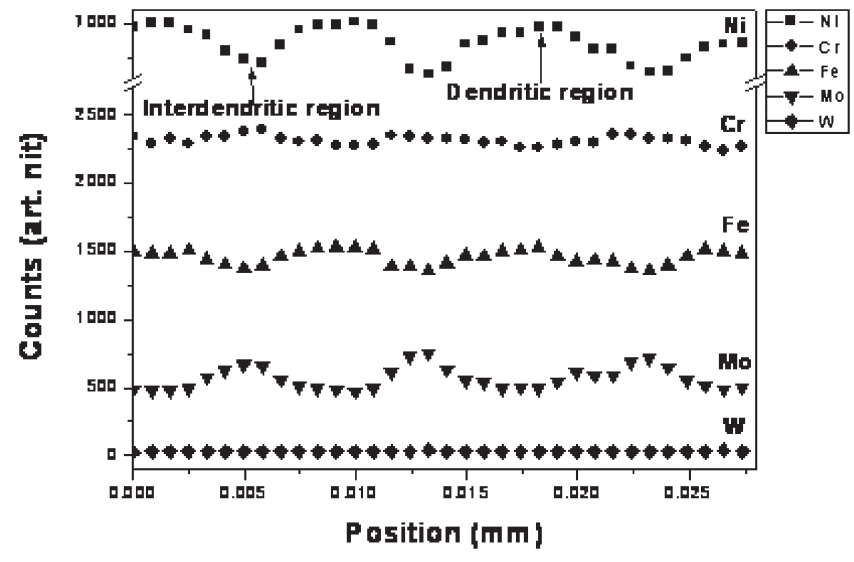

Fig. 6 (a) Back scattered electron (BSE) image and (b) electron probe micro-analyzer (EPMA) line analysis of the WM in the HDSS tubeto-tube sheet welded using a pure Ar shielding gas with a filler metal.

increases, the resistance of the alloy to pitting corrosion increases. Table 3 shows the electrochemical parameters measured from the potentiodynamic anodic polarization curves. The resistance to pitting corrosion of an alloy increases with an increase in the pitting potential, passive region $\left(\Delta E_{\mathrm{p}}\right)$, and with a decrease in the passive current density $\left(I_{\mathrm{p}}\right)$. The $E_{\mathrm{p}}\left(781 \mathrm{mV}_{\mathrm{SCE}}\right)$ and $\Delta E_{\mathrm{p}}\left(825 \mathrm{mV}_{\mathrm{SCE}}\right)$ of the HDSS tube-to-tube-sheet welded using the Ar shielding gas with a filler metal were higher than the $E_{\mathrm{p}}\left(146 \mathrm{mV}_{\mathrm{SCE}}\right)$ and $\Delta E_{\mathrm{p}}\left(203 \mathrm{mV}_{\mathrm{SCE}}\right)$ of the HDSS tube-to-tube-sheet welded using the Ar shielding gas without a filler metal.
Figure 8 presents the critical pitting temperature (CPT) and critical crevice temperature (CCT) of the HDSS tubeto-tube sheet welds in 6 mass $\% \mathrm{FeCl}_{3}+1$ mass $\% \mathrm{HCl}$ according to ASTM G 48-methods E and F, respectively. The CPT of the HDSS tube-to-tube sheet welded using the Ar shielding gas with a filler metal was $338 \mathrm{~K}$ whereas that of the HDSS tube-to-tube sheet welded using the Ar shielding gas without a filler metal was $318 \mathrm{~K}$. Furthermore, the CCT of the weld metal in the HDSS tube-to-tube sheet welded using the Ar shielding gas with a filler metal was $323 \mathrm{~K}$ whereas that of the weld metal in the HDSS tube-to-tube 


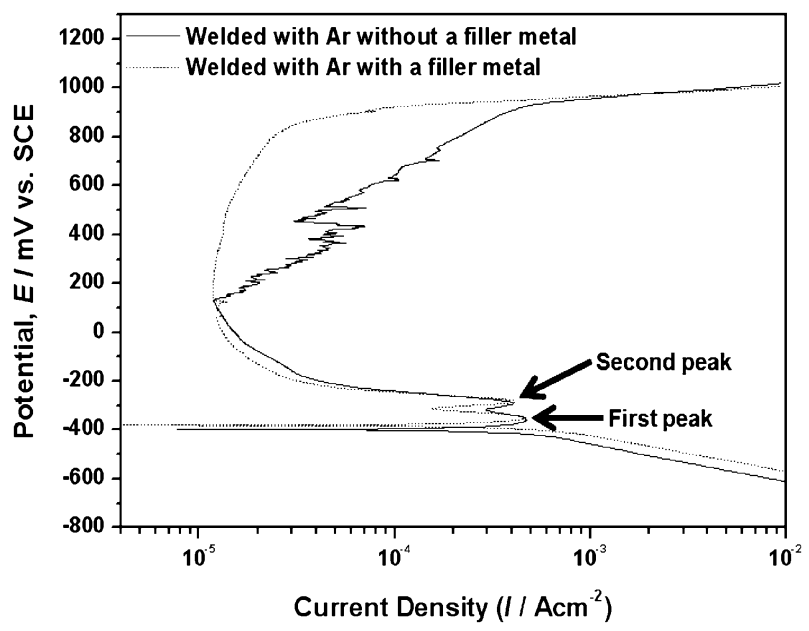

Fig. 7 The potentiodynamic anodic polarization behavior of the HDSS tube-to-tube sheet welds in a deaerated $0.5 \mathrm{~N} \mathrm{HCl}+1 \mathrm{~N} \mathrm{NaCl}$ at $333 \mathrm{~K}$ according to ASTM G 5 .

Table 3 Electrochemical parameters measured from the potentiodynamic anodic polarization curves in a deaerated $0.5 \mathrm{~N} \mathrm{HCl}+1.0 \mathrm{~N} \mathrm{NaCl}$ at $333 \mathrm{~K}$.

\begin{tabular}{|c|c|c|c|c|c|}
\hline \multirow{2}{*}{$\begin{array}{l}\text { Conditions of } \\
\text { shielding gas } \\
\text { and filler metal }\end{array}$} & \multirow{2}{*}{$\begin{array}{c}E_{\mathrm{P}}^{*}{ }^{*} \\
\left(\mathrm{mV}_{\mathrm{SCE}}\right)\end{array}$} & \multicolumn{2}{|c|}{$\Delta E_{\mathrm{P}}{ }^{* 2}\left(\mathrm{mV}_{\mathrm{SCE}}\right)$} & \multicolumn{2}{|c|}{$I_{\mathrm{P}}{ }^{{ }^{3} 3}\left(\mu \mathrm{A} / \mathrm{cm}^{2}\right)$} \\
\hline & & $\begin{array}{l}\text { First } \\
\text { peak }\end{array}$ & $\begin{array}{c}\text { Second } \\
\text { peak }\end{array}$ & $\begin{array}{l}\text { First } \\
\text { peak }\end{array}$ & $\begin{array}{c}\text { Second } \\
\text { peak }\end{array}$ \\
\hline Ar and no filler metal & 146 & 464 & 203 & - & - \\
\hline Ar and filler metal & 781 & 996 & 825 & 49 & 26 \\
\hline $\begin{array}{l}{ }^{{ }^{*} 1} E_{\mathrm{P}}: \text { Pitting potential } \\
{ }^{{ }_{2}} \Delta E_{\mathrm{P}}: \text { Passive region } \\
{ }^{{ }_{3}} I_{\mathrm{P}}: \text { Passive current de }\end{array}$ & & & & & \\
\hline
\end{tabular}

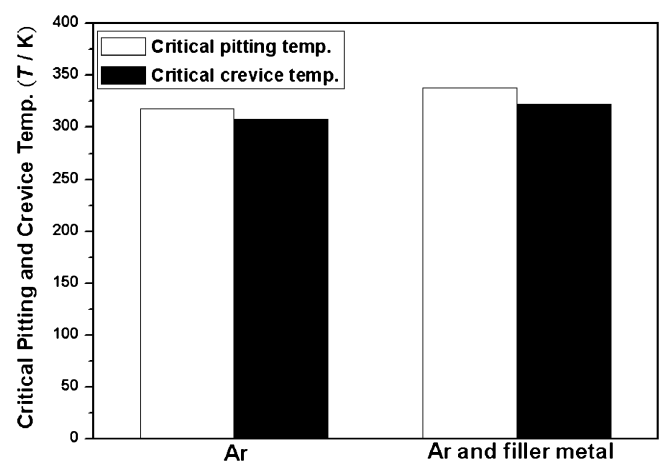

Fig. 8 The critical pitting and crevice temperature of the HDSS tube-totube sheet welds in 6 mass $\% \mathrm{FeCl}_{3}+1$ mass $\% \mathrm{HCl}$ according to ASTM $\mathrm{G}$ 48-methods $\mathrm{E}$ and $\mathrm{F}$, respectively.

sheet welded using the Ar shielding gas without a filler metal was $308 \mathrm{~K}$.

Based on the above results of the electrochemical, CPT and CCT tests, the resistance to localized corrosion of the HDSS tube-to-tube sheet welds after welding using the Ar shielding gas with a filler metal demonstrated a better corrosion resistance than the HDSS tube-to-tube sheet welds after welding using the Ar shielding gas without the filler metal in acidified $\mathrm{Cl}^{-}$environments.

\subsection{Mechanism of the localized corrosion of the HDSS tube-to-tube sheet welds}

Figure 9(a) presents the pitting morphologies of the weld (a)

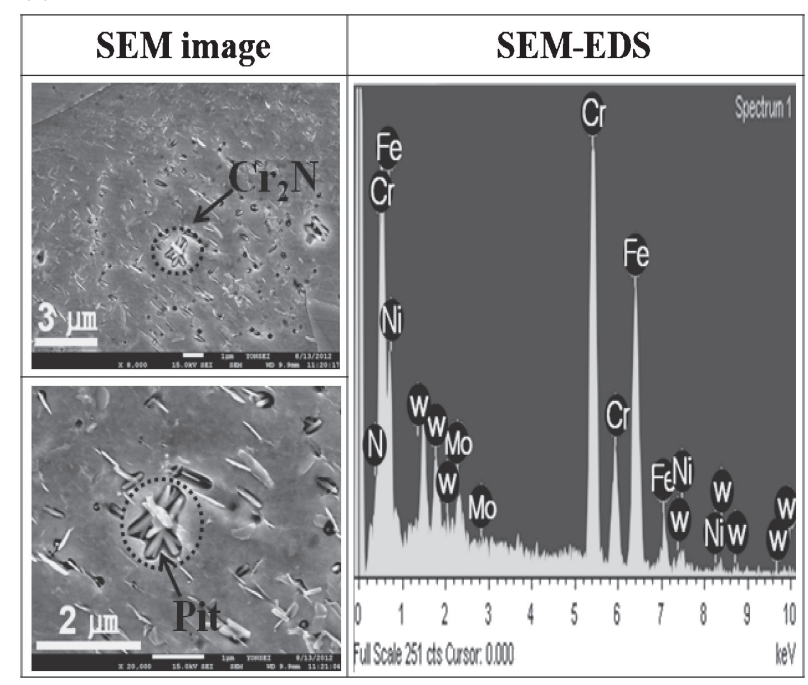

(b)

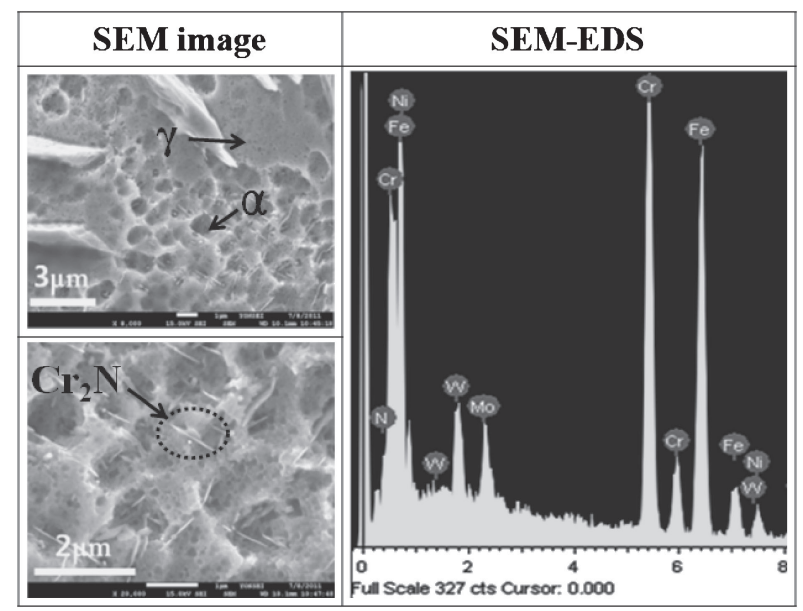

Fig. 9 The pitting morphologies of the weld metal (WM) in the HDSS tube-to-tube sheet welded using a pure Ar shielding gas without a filler metal: (a) after finishing the potentiodynamic polarization test at $600 \mathrm{mV}_{\mathrm{SCE}}$ and (b) after finishing the potentiodynamic polarization test at $950 \mathrm{mV}_{\mathrm{SCE}}{ }^{20)}$

metal (WM) in the HDSS tube-to-tube sheet welded using a pure Ar shielding gas without a filler metal after finishing the potentiodynamic polarization test at $600 \mathrm{mV}_{\mathrm{SCE}}$ whereas Fig. 9(b) shows those after finishing the potentiodynamic polarization test at $950 \mathrm{mV}_{\text {SCE}}$. That is, Fig. 9(a) indicates the pitting initiation because of finishing the potentiodynamic polarization test at $600 \mathrm{mV}_{\mathrm{SCE}}$ above the pitting potential of $146 \mathrm{mV}_{\mathrm{SCE}}$ whereas Fig. 9(b) indicates the pitting propagation because of finishing the potentiodynamic polarization test at $950 \mathrm{mV}_{\mathrm{SCE}}$ much higher than the pitting potential of $146 \mathrm{mV}_{\mathrm{SCE}}$. The pitting corrosion of the WM $(85 \mathrm{vol} \% \alpha)$ containing the high $\alpha$-phase in the HDSS tube-to-tube sheet welds was initiated at the $\mathrm{Cr}$-depleted zone adjacent to the $\mathrm{Cr}_{2} \mathrm{~N}$ in the $\alpha$-phase (Fig. 9(a)) and was then propagated into the $\alpha$-phase (Fig. 9(b)).

Figure 10 presents the pitting morphologies of the weld metal (WM) and heat affected zone (HAZ) in the HDSS tubeto-tube sheet welded using a pure Ar shielding gas with a filler metal after the potentiodynamic polarization test. The pitting corrosion at the WM occurred at the dendrite core 
(a)

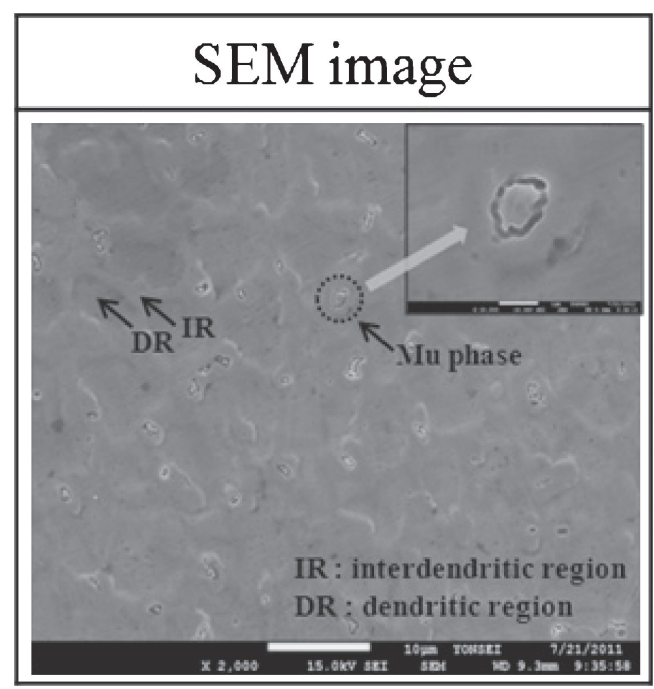

(b)

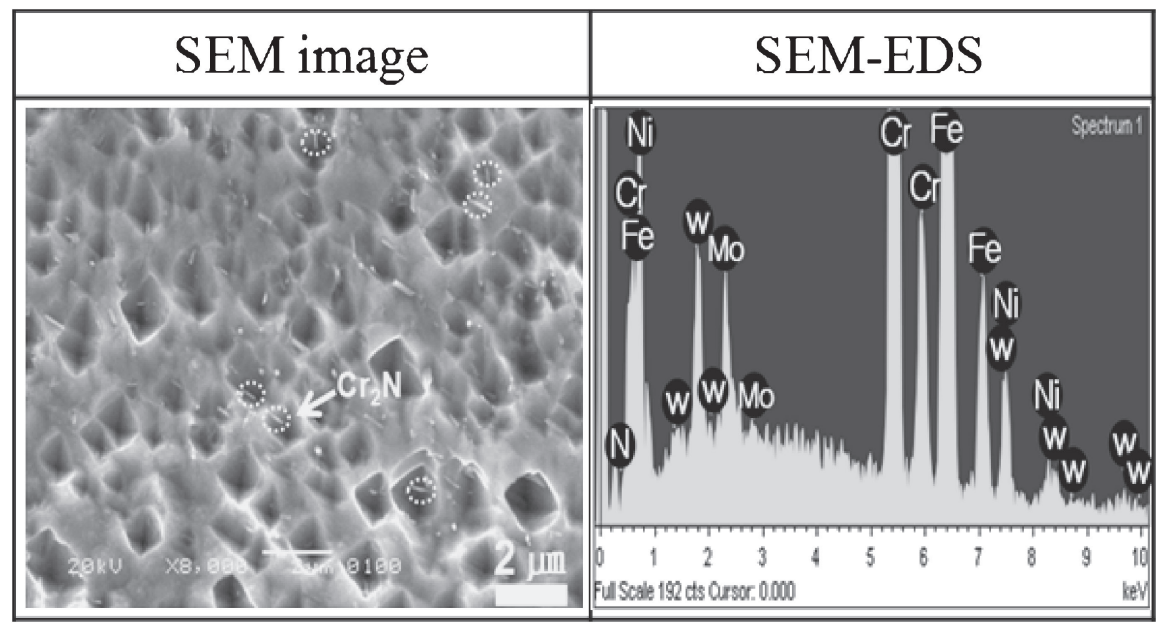

Fig. 10 The pitting morphologies of the weld metal (WM) and heat affected zone (HAZ) in the HDSS tube-to-tube sheet welded using a pure Ar shielding gas with a filler metal after the potentiodynamic polarization test: (a) the weld metal (WM) and (b) heat affected zone (HAZ).

(DC) that $\mathrm{Cr}$ and Mo were depleted, and at the region adjacent to the $\mu$-phase that Mo and $\mathrm{W}$ were depleted. The pitting corrosion of the HAZ ( 63 vol $\% \alpha$ ) containing the high $\alpha$-phase was initiated due to an increase of the $\mathrm{Cr}$-depleted zone adjacent to the rod-like $\mathrm{Cr}_{2} \mathrm{~N}$ in the $\alpha$-phase.

Figure 11 shows the initiation and propagation of pitting corrosion of the HDSS tube-to-tube sheet welds after the critical pitting test in 6 mass $\% \mathrm{FeCl}_{3}+1$ mass $\% \mathrm{HCl}$. Irrespective of the Ar shielding gas, filler metal and the areas of the WM and HAZ (except for the WM in the HDSS tube-to-tube sheet welded using Ar with a filler metal), the pitting corrosion was initiated at the $\alpha$-phase, and was then propagated into the $\gamma$-phase. The final propagation of pitting corrosion occurred partly from the $\alpha$-phase to the $\gamma$-phase and most of the non-pitted $\gamma$-phases adjacent to the completely pitted $\alpha$-phases jumped to the test solution. However, the pitting corrosion of the WM in the HDSS tube-to-tube sheet welds after welding using the pure Ar with a filler metal seems to occur at the region adjacent to $\mathrm{Mu}$ phase that Mo and $\mathrm{W}$ were depleted.

To verify the difference in the resistance to pitting corrosion between the $\gamma$-phase and the $\alpha$-phase, the content of Cr, Mo and W in the $\gamma$-phase and the $\alpha$-phase in the HDSS tube-to-tube sheet welds was quantitatively measured using a SEM-EDS and the N content was measured using a SAM. Then, the pitting resistance equivalent number (PREN) values of the $\gamma$-phase and the $\alpha$-phase in the WM, HAZ and BM were calculated.

PREN formula (3) for DSSs has been used by several researchers to investigate the resistance to localized corrosion of DSSs. ${ }^{21,27,28)}$

$$
\begin{aligned}
\text { PREN }= & \text { mass } \% \mathrm{Cr}+3.3(\operatorname{mass} \% \mathrm{Mo}+0.5 \text { mass } \% \mathrm{~W}) \\
& +30 \text { mass } \% \mathrm{~N}
\end{aligned}
$$

Figure 12 shows the difference of the PRE $\left(\mathrm{PREN}_{\gamma}-\right.$ $\operatorname{PREN}_{\alpha}$ ) value between the $\alpha$-phase and the $\gamma$-phase of the HDSS tube-to-tube sheet welds. Based on the $\operatorname{PREN}_{\gamma}$ and $\mathrm{PREN}_{\alpha}$ values calculated by eq. (3) with a nitrogen factor of 30 , the pitting corrosion must selectively generate at the $\alpha$ phases in acidified $\mathrm{Cl}^{-}$environment, irrespective of the $\mathrm{Ar}$ shielding gas, filler metal, and the areas of the WM, HAZ and $\mathrm{BM}$ (except for the WM in the HDSS tube-to-tube sheet welded using Ar with a filler metal) because the PREN value of the $\gamma$-phase is much larger than that of the $\alpha$-phase. 


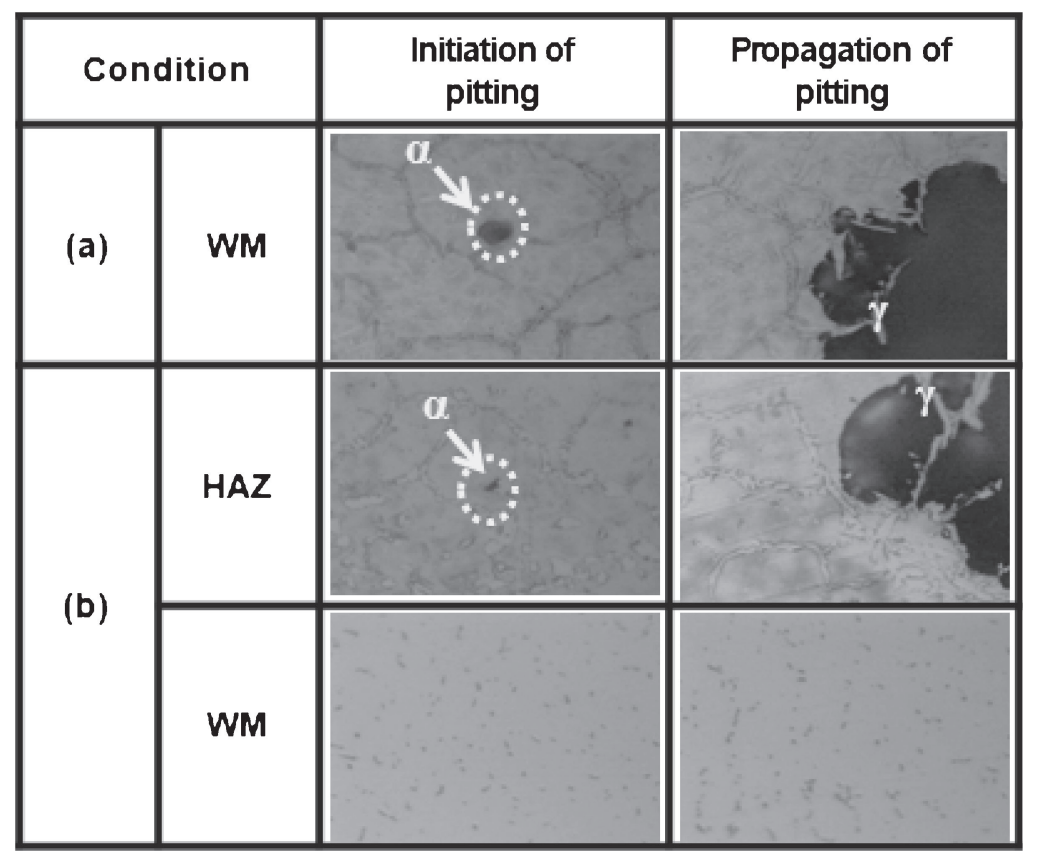

Fig. 11 The initiation and propagation of pitting corrosion of the HDSS tube-to-tube sheet welds after the critical pitting test in 6 mass $\%$ $\mathrm{FeCl}_{3}+1$ mass $\% \mathrm{HCl}$ : (a) welded with Ar without filler metal ${ }^{20)}$ and (b) welded with Ar with filler metal.

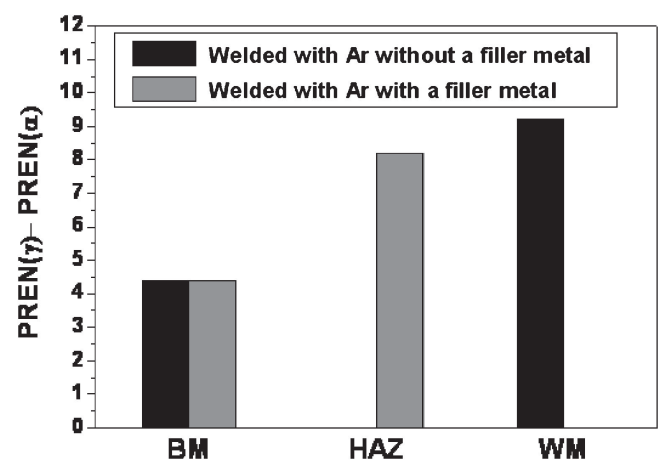

Fig. 12 The PREN difference $\left(\mathrm{PREN}_{\gamma}-\mathrm{PREN}_{\alpha}\right.$ ) between the $\gamma$-phase and the $\alpha$-phase of the HDSS tube-to-tube sheet welds.

The HDSS tube-to-tube sheet welds showed the differences in the PREN between these two phases in the following order: WM (Ar without a filler metal) $>$ HAZ (Ar with a filler metal) $>$ BM. The differences in the PREN between these two phases in the WM and HAZ of the HDSS are much larger than those of the BM. Accordingly, the difference of corrosion resistance between the two phases is greatly increased, and thereby deteriorating the corrosion resistance at the WM and HAZ. As presented in Figs. 4 and 12, the PREN difference $\left(\mathrm{PREN}_{\gamma}-\mathrm{PREN}_{\alpha}\right)$ between the two phases is proportional to the ferrite $(\alpha)$ content. As the content of the $\alpha$-phase increases and that of the $\gamma$-phase decreases, Cr, Mo and $\mathrm{W}$, which act as $\alpha$-stabilizers, are diluted in the $\alpha$-phase and are enriched in the $\gamma$-phase. In contrast, nitrogen, which is a $\gamma$-stabilizer, is restricted to a maximum of 0.05 mass $\%$ due to the small interstitial site of the BCC structure in the $\alpha$-phase and is almost enriched in the $\gamma$-phase.

Figure 13 the schematic of the localized corrosion and phase transformation of the HDSS tube-to-tube sheet welds. The $\alpha$-phase fraction and $\mathrm{Cr}_{2} \mathrm{~N}$ content in the WM after welding using the Ar shielding gas without a filler metal was increased greatly during the cooling period (Fig. 13(b)), compared with that of the BM (Fig. 13(a)), and thereby initiating the pitting corrosion at the Cr-depleted region adjacent to $\mathrm{Cr}_{2} \mathrm{~N}$ precipitated in the $\alpha$-phase.

Moreover, the content of the $\alpha$-phase in the HAZ of the HDSS tube-to-tube sheet welded using the Ar shielding gas with a filler metal was increased (Fig. 13(e)), when compared with that of the HDSS welded using the Ar shielding gas without a filler metal (Fig. 13(d)). Meanwhile, the WM of the HDSS tube-to-tube sheet welded using pure Ar with a filler metal (Fig. 13(c)) was composed the interdendritic region (IR), dendritic region (DR) and Mu phase. The pitting corrosion occurred at the $\mathrm{Cr}$ and Mo-depleted region in the DR and at the Mo and W-depleted region adjacent to $\mathrm{Mu}$ phase.

Accordingly, as the ferrite content increases, the amount of $\mathrm{Cr}_{2} \mathrm{~N}$ and PREN difference between the $\alpha$-phase and $\gamma$-phase increase. Here, the order of priority of the localized corrosion resistance is as follows: $\gamma$-phase $>\alpha$-phase $>\mathrm{Cr}$-depleted zone. Hence, the resistance to localized corrosion was decreased after welding using Ar shielding gas without a filler metal, compared with that of the Ar shielding gas with a filler metal.

\section{Conclusions}

To elucidate the mechanism of localized corrosion and phase transformation of the HDSS tube-to-tube sheet welds investigated in acidified chloride environments, a metallographic examination, a potentiodynamic polarization test, critical pitting and crevice temperature tests, scanning electron microscope and energy dispersive spectroscope (SEM-EDS) analyses, a scanning Auger multi-probe (SAM) analysis and an electron probe micro-analyzer (EPMA) were carried out. From the results of these tests, the following conclusions have been drawn. 


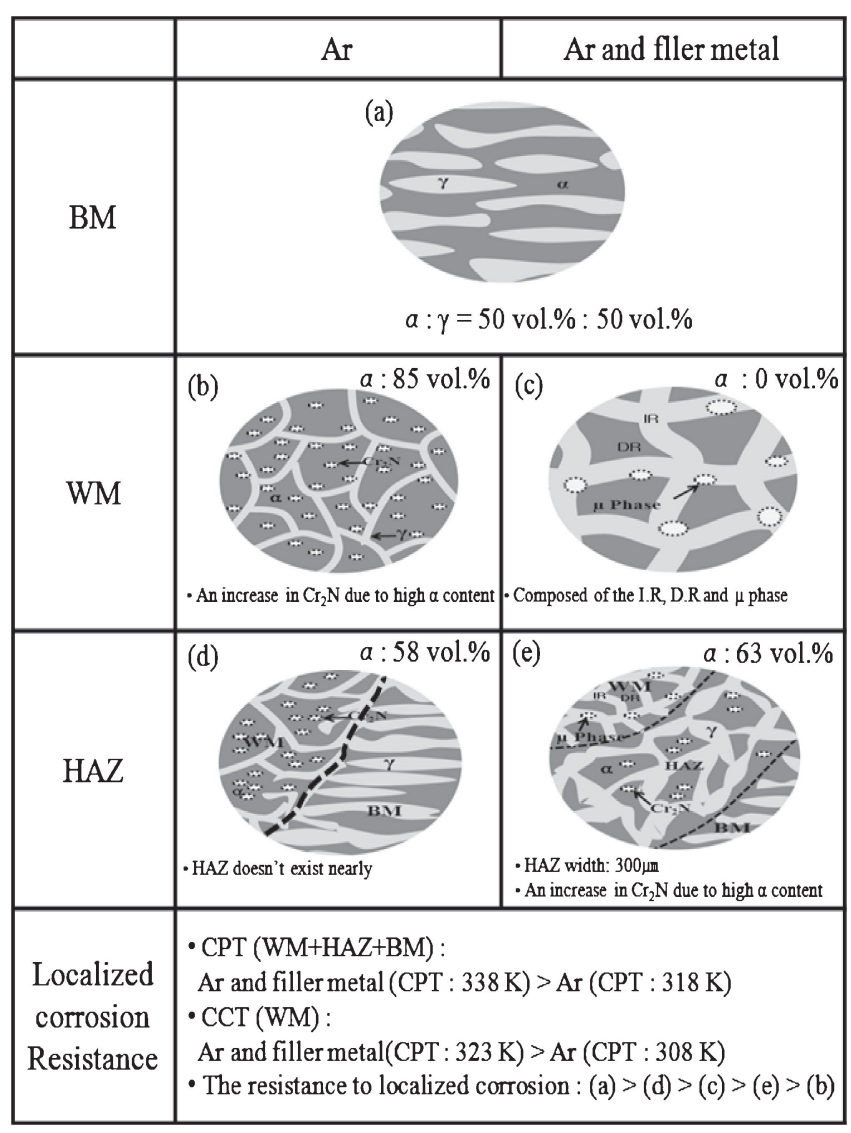

Fig. 13 Schematic of the localized corrosion and phase transformation of the HDSS tube-to-tube sheet welds: (a) base metal (BM), (b) weld metal (WM) and (d) heat affected zone HAZ of the HDSS tube-to-tube sheet welded using the Ar shielding gas without a filler metal, and (c) WM and (e) HAZ of the HDSS tube-to-tube sheet welded using the Ar shielding gas with a filler metal. *Base Metal: BM, Heat Affected Zone: HAZ, Weld Metal: WM, Interdendritic Region: IR, Dendritic Region: DR, Mu phase: $\mu$ phase, Critical Pitting Temp.: CPT, Critical Crevice Temp.: CCT.

(1) The resistance to localized corrosion of the weld metal (WM) in the HDSS tube-to-tube sheet welded with an Ar shielding gas without a filler metal decreased greatly due to an increase in the $\alpha$-phase fraction $(85$ vol\% $\alpha)$ and $\mathrm{Cr}_{2} \mathrm{~N}$, and an increase in the pitting resistance equivalent number (PREN) difference between the $\gamma$ phase and $\alpha$-phase, compared with that of the base metal (BM).

(2) The pitting corrosion of the WM in the HDSS tube-totube sheet welded using a pure Ar shielding gas with a filler metal occurred at the dendrite core (DC) that $\mathrm{Cr}$ and Mo were depleted and at the region adjacent to the $\mu$-phase that Mo and $\mathrm{W}$ were depleted. The pitting behavior of the HAZ (63 vol\% $\alpha$ ) was similar to that of the WM in the HDSS tube-to-tube sheet welded with an Ar shielding gas without a filler metal.

(3) Based on the PREN ${ }_{\gamma}$ and $\mathrm{PREN}_{\alpha}$ values, the localized corrosion of the HDSS tube-to-tube sheet welds was selectively initiated at the $\alpha$-phases because the PREN value of the $\gamma$-phase is much larger than that of the $\alpha$ phase, irrespective of the areas of the WM, HAZ and
BM (except for the WM in the HDSS tube-to-tube sheet welded using Ar with a filler metal). The localized corrosion was finally propagated from the $\alpha$-phase to the $\gamma$-phase.

(4) Based on the results of the electrochemical, CPT and CCT tests, the resistance to localized corrosion of the HDSS tube-to-tube sheet welded using a pure Ar shielding gas with a Ni-based filler metal is superior to that of the HDSS tube-to-tube sheet welded using pure Ar without the filler metal.

\section{Acknowledgements}

This work has been supported by Ministry of Knowledge Economy of the Republic of Korea.

\section{REFERENCES}

1) J. O. Nilsson: Mater. Sci. Technol. 8 (1992) 685-700.

2) J. Olson and S. Nordin: Proc. Duplex Stainless Steel '86, (1986) pp. 219-225.

3) E. Perteneder, J. Tosch, P. Reiterer and G. Rabensteiner: Proc. Duplex Stainless Steel '86, (1986) pp. 48-56.

4) The International Molybdenum Association (IMOA): Practical Guidelines for the Fabrication of Duplex Stainless Steel, (Pergamon Press, 2009) pp. 1-64.

5) H. Okamoto: Proc. Applications of Stainless Steels '92, Vol. 1, (1992) pp. 360-368.

6) S. Atamert and J. E. King: Mater. Sci. Technol. 8 (1992) 896-911.

7) P. J. Ferreira and S. Hertzman: Proc. Duplex Stainless Steel '91, Vol. 2, (1991) pp. 959-966.

8) B. E. S. Lindblom, B. Lundqvist and N. E. Hannerz: Proc. Duplex Stainless Steel '91, Vol. 1, (1991) pp. 373-382.

9) H. L. Cao and S. Hertzman: Proc. Duplex Stainless Steel '91, Vol. 1, (1991) p. 363-372.

10) B. E. S. Lindblom and N. Hannerz: Proc. Duplex Stainless Steel '91, Vol. 2, (1991) pp. 951-958.

11) U. Draugelates, A. Schram, C. Boppert and J. Liu: Proc. Duplex Stainless Steel '91, Vol. 2, (1991) pp. 977-984.

12) S. A. Urmston, G. K. Creffield, M. A. Cole and W. Huang: Proc. Duplex Stainless Steel '94, Vol. 2, (1994) Paper 27.

13) X. G. Wang, D. Dumortier and Y. Riquier: Proc. Duplex Stainless Steel '91, 1, (1991) pp. 127-134.

14) R. Taylor: Duplex Stainless Steel Production, SFSA T\&O Conference, (1994).

15) J. C. Lippold, W. Lin, S. Brandi, I. Varol and W. A. Baeslack III: Proc. Duplex Stainless Steels '94, 1, (1994) Paper 116.

16) E. I. Kivineva and N. E. Hannerz: Proc. Duplex Stainless Steels '94, 1, (1994) Paper 7.

17) Annual Book of ASTM Standards, ASTM E562-02.

18) Annual Book of ASTM Standards, ASTM G 5-04.

19) Annual Book of ASTM Standards, ASTM G 48-method E and F.

20) S. T. Kim, I. S. Lee, J. S. Kim, S. H. Jang, Y. S. Park, K. T. Kim and Y. S. Kim: Corro. Sci. 64 (2012) 164-173.

21) S. Bernhardsson: Duplex Stainless Steels '91, 1, (1991) pp. 185-210.

22) P. I. Marshall and T. G. Gooch: Corrosion 49 (1993) 515-526.

23) K. Zhao, Y. H. Ma, L. H. Lou and Z. Q. Hu: Mater. Trans. 46 (2005) 54-58.

24) Y. R. Zheng: Acta Metall. Sinica 35 (1999) 12-18.

25) H. M. Tawancy: J. Mater. Sci. 31 (1996) 3929-3936.

26) C. T. Sims and W. C. Hagel: The Superalloys, (John Wiley \& Sons, 1972) p. 264.

27) M. Barteri, M. G. Mecozzi and I. Nembrini: Duplex Stainless Steels '94, 3, (1994) Paper 60.

28) M. Renner, U. Heubner, M. U. Rockel and E. Wallis: Werkst. Korros. 37 (1986) 183-190. 